\title{
Structural Transformations in Ti-6Al-4V Alloy
}

\author{
P. Tarín, F.X. Gil*, M.P. Ginebra*, J.M. Manero*, J.M. Prado*, M. Solé** and J.A. Planell*
}

Dept. Cienca de Materiales, E.T.S. Ingenieros Aeronauticos, Universidad Politécnica de Madrid, Spain * Dept. Cienca de los Materiales e Ingeniería Metalúrgica, E.T.S. Ing. Industriales de Barcelona, Universidad Politécnica de Cataluña, Av. Diagonal 647, 08028-Barcelona, Spain

** Dept. Cienca de los Materiales e Ingeniería Metalúrgica, E.U. Politécnica de Manresa, Universidad Politécnica de Cataluña, Spain

\begin{abstract}
The transformation kinetics, transformation products, $M_{s}$ and $M_{f}$ temperatures and time-temperature transformation diagram have been investigated. These phase transformations have been studied by means of the dilatometric analysis, optical and electron microscopy and hardness tests.

Martensitic transformation and its decomposition when it is heat treated, has also been studied at different temperatures. This ageing process provides better hardness values than the original martensitic structure.
\end{abstract}

\section{INTRODUCTION}

Phase transformations in titanium alloys have been of considerable interest to materials scientists because of the wide variety of crystallographic phases that can be observed. Much work has been done in the study of the allotropic phase transformation between alpha titanium with the hexagonal-close packed (hcp) structure and beta titanium, which is body centered cubic (bcc). This has resulted in the development of a range of commercial alloys based on the addition of either, or in some cases both, alloying additions that stabilize the alpha or beta phases.

One of the most widely used titanium alloys is an alpha-beta type containing $6 \% \mathrm{Al}$ and $4 \% \mathrm{~V}$. The Ti-6Al-4V alloy has an excellent combination of strength and toughness along with an excellent corrosion resistance (1-5).

When this alloy is slowty cooled from the $\beta$ phase region, $\alpha$ phase begins to form below the $\beta$ transformation temperature, which is about $1020^{\circ} \mathrm{C}$. Upon slow cooling a nucleus of $\alpha$ forms and grows as plates; this microstructural morphology, consists of sets of parallel $\alpha$ plates surrounded by the $\beta$ phase precipitated between them.

Upon cooling rapidly, $\beta$ phase may decompose through martensitic reaction. A distinction can be made between 
relatively dilute $\alpha \beta$ alloys which form hexagonal $\alpha$ martensite or two orthorombic martensites $\alpha^{\prime \prime}$ and $\alpha^{\prime \prime \prime}$ depending on the chemical composition and quenching conditions, and more concentrated alloys in which the $\beta$-phase may be partly or completely retained in a metastable condition. The Ti-6Al-4V alloy corresponds to the hexagonal type. The martensite forms as colonies of parallel plates or laths, whose boundaries of which consist of walls of dislocations (3).

$\alpha^{\prime}$ martensite transforms on heating at elevated temperatures by several reactions. $\alpha^{\prime}$ descomposes directly to $\alpha$ phase of equilibrium composition at the tempering temperature and $\beta$ phase forms as a fine precipitate that is nucleated heterogeneously at martensite plate boundaries or at internal substructures such as twins (3).

\section{EXPERIMENTAL METHOD}

The chemical composition of the Ti-6Al-4V used is shown in Table I Its initial microstructure was of "mill annealed" type as can be seen in Figure 1.

Table I Chemical composition (\% weight)

\begin{tabular}{|c|c|c|c|c|c|c|}
\hline $\mathrm{Al}$ & $\mathrm{V}$ & $\mathrm{Fe}$ & $\mathrm{C}$ & $\mathrm{O}_{2}$ & $\mathrm{~N}_{2}$ & $\mathrm{H}_{2}$ \\
\hline 6.0 & 4.0 & 0.11 & 0.021 & 0.09 & 0.010 & 0.003 \\
\hline
\end{tabular}

Three different series of thermal treatment were carried out

A) Continuous cooling treatments. Specimens of $3 \mathrm{~mm}$ in diameter and $12 \mathrm{~mm}$ long were solution heated at temperature of 1100 and $1050^{\circ} \mathrm{C}$ for 10 minutes and then brought to room temperature at cooling velocities of $0.24,0.70,1.41$ and $3.40^{\circ} \mathrm{C} / \mathrm{s}$. A Sadamel 18 AVRF-2 dilatometer was used for this type of thermal treatment Specimens were previously nickel coated in order to avoid oxidation.

B) Isothermal treatments. Disk-shaped specimens of $10 \mathrm{~mm}$ in diameter and $1 \mathrm{~mm}$ thick were solution heated at $1050^{\circ} \mathrm{C}$ for 30 minutes and then held at temperatures between 600 and $950^{\circ} \mathrm{C}$ (with temperature intervals of $50^{\circ} \mathrm{C}$ ). Lead and neutral salt bath were used to cover the whole range of holding temperatures

C) Martensitic treatments. Disk-shaped specimens of $12 \mathrm{~mm}$ in diameter and $3 \mathrm{~mm}$ thick were solution heated at $1050^{\circ} \mathrm{C}$ for 30 minutes and water cooled to room temperature. Annealing treatment at temperatures of 400,700 and $800^{\circ} \mathrm{C}$ were also applied to these samples for $5,10,15,30,60$ and 120 minutes for each one.

Microstructure was studied by optical and scanning electron microscopy. Microstructural parameters were determined by means of automatic image analysis. Vickers hardness measurements were done by applying a load of $1000 \mathrm{~g}$ during 15 seconds. 
The isothermal treatments have allowed to obtain the TTT diagram of this titanium alloy, shown in Fig2. The $\mathrm{M}_{\mathrm{s}}$ and $\mathrm{M}_{\mathrm{f}}$ temperatures have been determined to be very close to $800^{\circ} \mathrm{C}$ and $630^{\circ} \mathrm{C}$, respectively. Between the $\beta$-transus $\left(1000^{\circ} \mathrm{C}\right)$ and the $M_{s}$ temperatures the $\beta$ phase transforms into $\alpha+\beta$, the beginning of this transformation is indicated by the solid line, while the dashed line corresponds to the moment when no more structure evolution is microscopically detected Betwen $\mathrm{M}_{s}$ and $\mathrm{M}_{\mathrm{f}}$ takes place the athermal martensitic transformation, with increasing amount of $\alpha^{\prime}$-phase being formed as holding temperature is decreased.

The $\alpha$-phase obtained in this way is not stable and with longer holding times decomposes into the $\alpha$ and $\beta$ phases. Also, the retained $\beta$ phase partially transforms into $\alpha$-phase. The solid line in this region of the TTT diagram indicates the beginning of the $\alpha^{\prime}$ ageing and retained metaestable $\beta_{m}$ decomposition.

Direct water quench from $1050^{\circ} \mathrm{C}$ gave place to fully martensitic structures as can be shown in Fig 3, with a Vickers hardness of 330. Posterior annealing of these martensitic specimens produced different amounts of $\alpha$ 'decomposition depending on temperature and holding time. Hardness evolution with annealing is shown in Fig.4. At each temperature the curve of hardness versus holding time is sigmoidal type indicating that the precipitation of the $\alpha$ and $\beta$ phases from $\alpha^{\prime}$ occurs by a nucleation and growth process controlled by atom diffiusion.

At low annealing temperatures (below $600^{\circ} \mathrm{C}$ ) the decomposition of $\alpha^{\prime}$ is incomplete as is shown by the small value of the hardness. Figure 4 shows that at $400^{\circ} \mathrm{C}$ the precipitation of $\alpha$ and $\beta$ stops after 40 minutes with a hardness of 350. The incomplete nature of the precipitation at this temperature can also be observed in Fig. 5 , which shows the microstructure of a specimen annealed at $400{ }^{\circ} \mathrm{C}$ for 60 minutes. At temperatures above $\mathrm{M}_{f}$ the decomposition of $\alpha$ reaches completion, this fact is reflected in the high saturation value showed by hardness (410 HV). The microstructure obtained at these high annealing temperatures is shown in Fig6, only $\alpha$ and $\beta$ phases are now present.

The initial purpose of the dilatometric continous cooling treatments was twofold: to determine the CCT curve of this alloy and to study the effect of well defined cooling continous conditions on microstructural parameters such as $\alpha$-plate thickness.

The CCT curve could not be determined because the dilatometric behaviour of titanium alloys is highly anomalous. In Fig 7 three differential dilatometric curves, two heating and one cooling cycles, are shown. It is possible to observe how in the two heating cycles dilatations of opposite sign occur, furthermore the temperatures where dilatation anomalies are observed. This anomalous dilatometric behaviour of titanium has been attributed to different causes such as texture, oxigen absorption and de-absorption (6).

Continous cooling treatments gave place to the well known "basket weave" structure of $\alpha$ plates (7-8). The effect of solution temperature and cooling velocity on the width of the $\alpha$ plates is shown in Fig. 8. Plates become thinner as cooling velocity increases. In Fig. 9 the presence of $\alpha$ allotromorphs from where the Widmanstatten $\alpha$ side plates grow can be seen. The reason for the transition from grain boundary allotromorphs to the Widmanstatten structure is not well understood, but it sems related to the fact that plain interfaces are formed by coherent and incoherent areas. At low undercoolings (low cooling velocities) the migration rates of both types of interfaces are similar, probably due to solute segregation to the incoherent interfaces. At high undercooling (high cooling velocities) segregation is hampered and incoherent interfaces can grow faster giving place to the 
plate-like morphology (9). Even it can take the aspect of bainitic type structure formed by repeated $\alpha$ plate nucleation, as can be seen in Fig.10.

\section{ACKNOWLEDGEMENTS}

The authors would like to thank the CCYT for funding this work through project MAT90-0755.

\section{REFERENCES}

1. Donachie J. "Titanium. A Technical Guide". A.S.M. Intemational. Ohio (1988) pp. 21-36.

2. Tarín P. "Titanio y sus aleaciones". Apuntes del curso "Materiales Avanzados" CEAM Ed. Barcelona (1989). pp. 10-25.

3. Polmear IJ. "Light alloys". Edward Amold. Londres. (1981).

4. Collings E.W. "The physical metallurgy of Titanium Alloys". American Society for Metals. Ohio. (1984).

5. Manero J.M, Gil FJ., Vázquez J.J. and Planell J.a Anales de Mecánica de la Fractura 10 (1993) 113-119.

6. English J., Powell G.W. "Thermal dilatation behaviour of titanium alloy during repeated cycling trough the alpha-beta transformation". Trans of the Metallurgical Society of AIME, vol. 236 (1986) pp. 1467-1473.

7. Gil F.J., Femández E., Arcas R. and Planell J.A. Biomecánica 2 (1993) 51-53.

8. Gil F.J., Marsal M, Manero JM, Planell J.A. "Study of the microstructure of the mill annealed Ti-6Al-4V". Proceedings of X European Congress on Electron Microscopy. EUREM-92. Granada University Ed. Granada (1992) 253-255.

9. Porter D.A., Easterling KE. "Phase transformations in Metals and Alloys". Van Nostrand Reinhold. New York. (1981). 382-401.
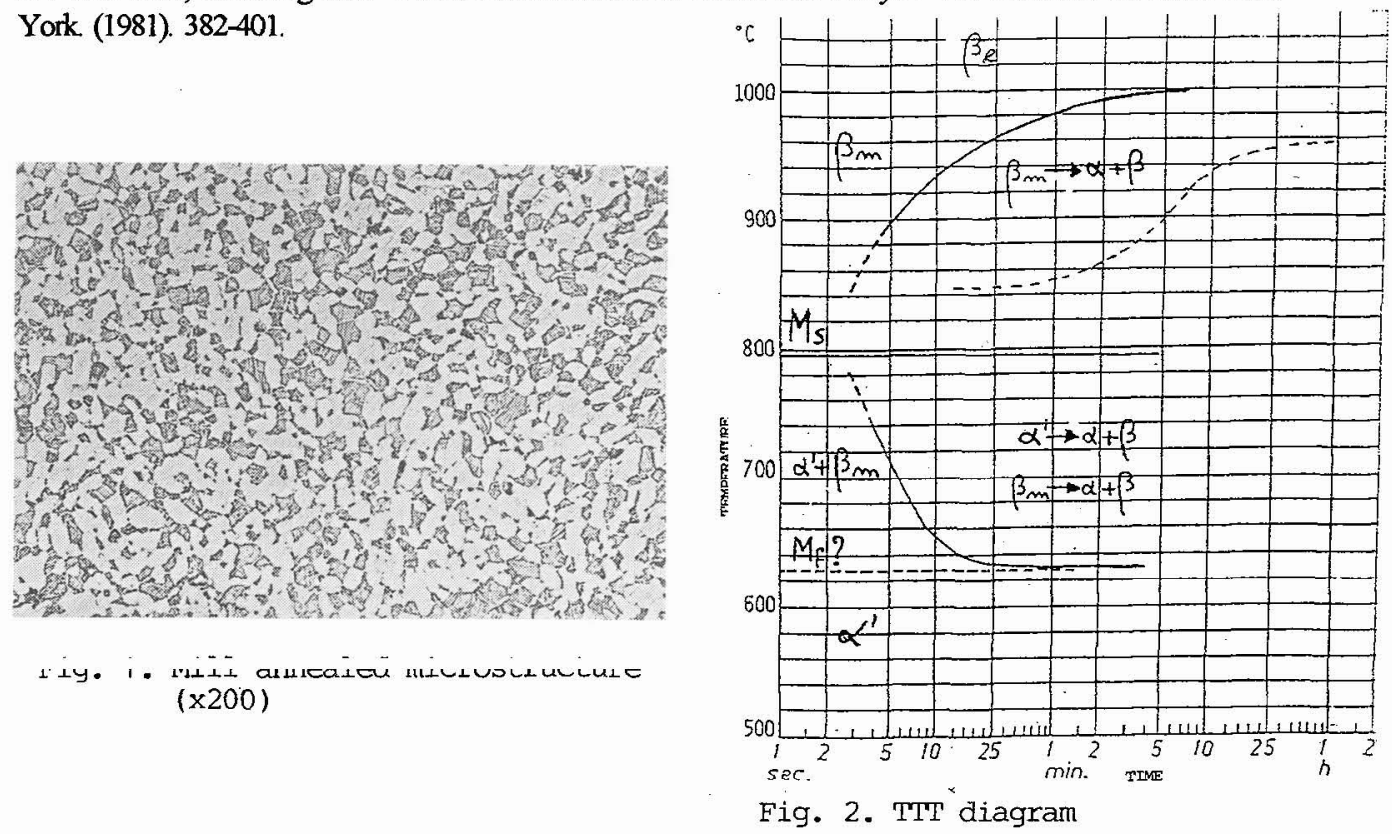


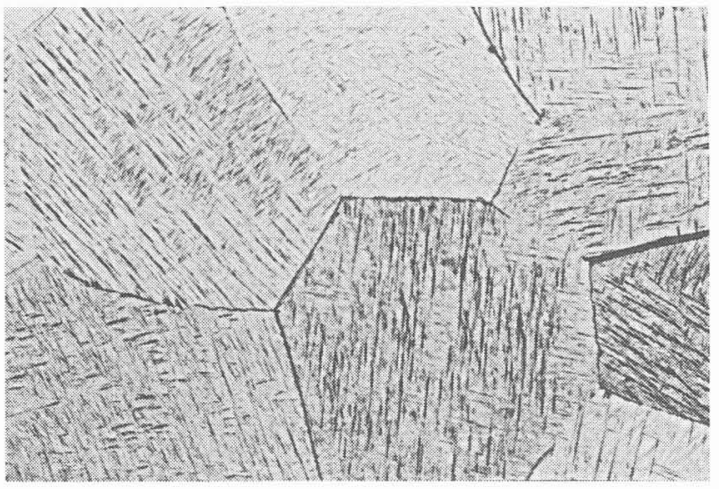

Fig.3. Martensitic microstructure (x150)

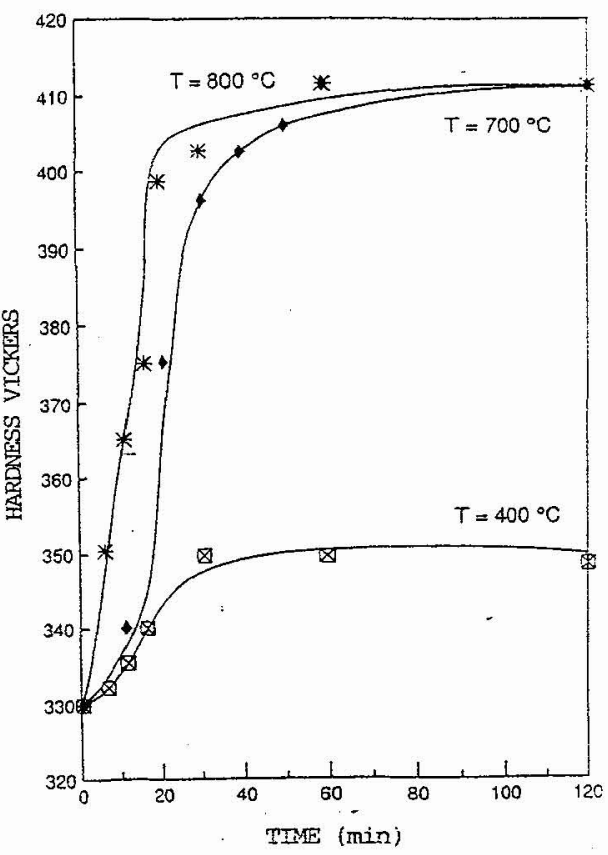

Fig.4. Hardness versus annealing times for different temperatures

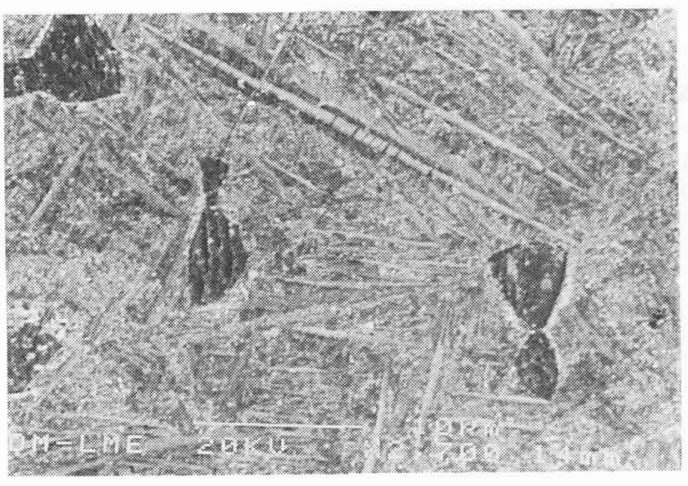

Fic-5. Micrnstmicture of a specimen annealed at $400^{\circ} \mathrm{C}$ for $60 \mathrm{~min} .(x 2700)$

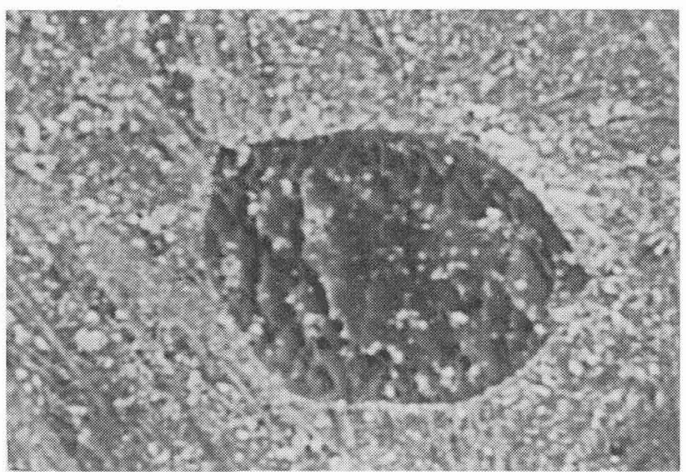

Fic.6. Microstmeture of a specimen annealed at $100^{\circ} \mathrm{C}$ for $30 \mathrm{~min} .(\mathrm{x} 2700)$ 


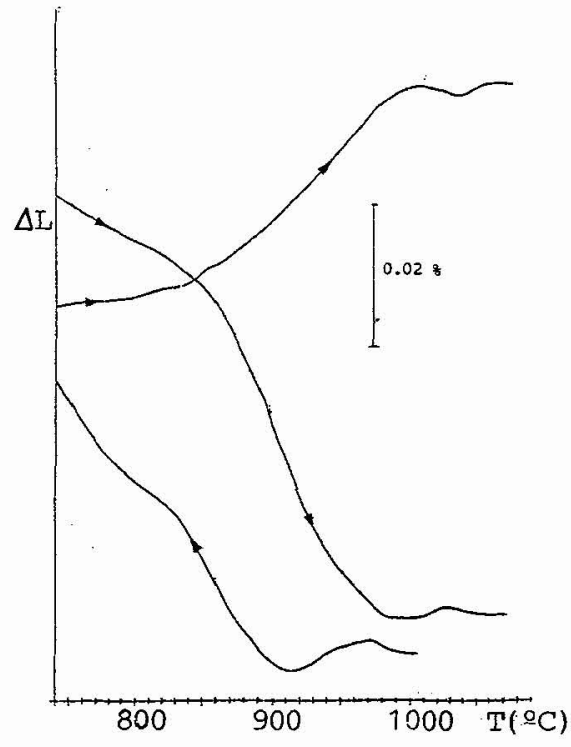

Fig.7. Differential dilatometric curves

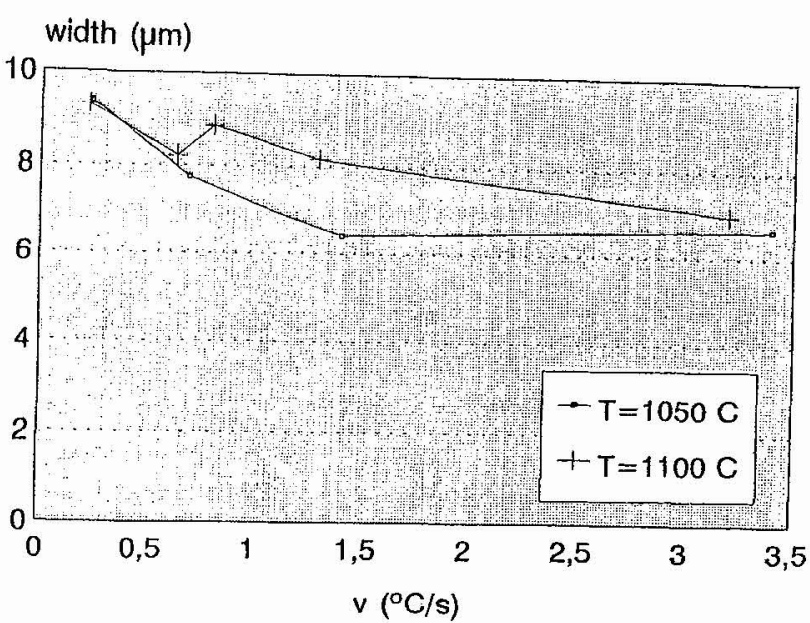

Fig. 8. Width of the $\alpha$ plates versus cooling velocities. at different temperatures

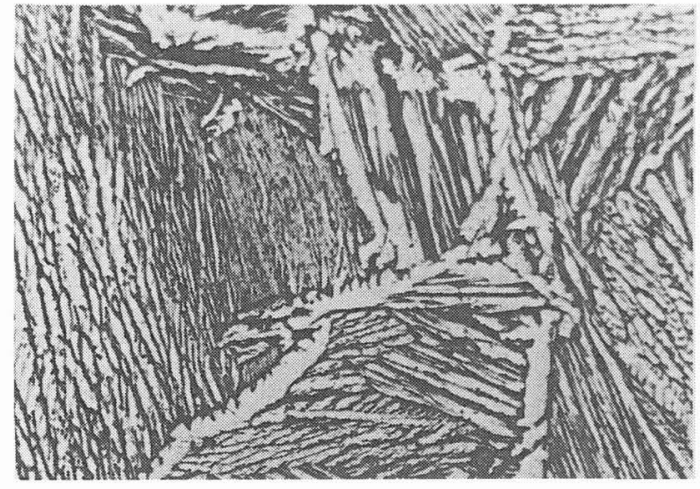

Fig.9. $\alpha$ allotromorphs in widmanstatten microstructure. $(x 200)$

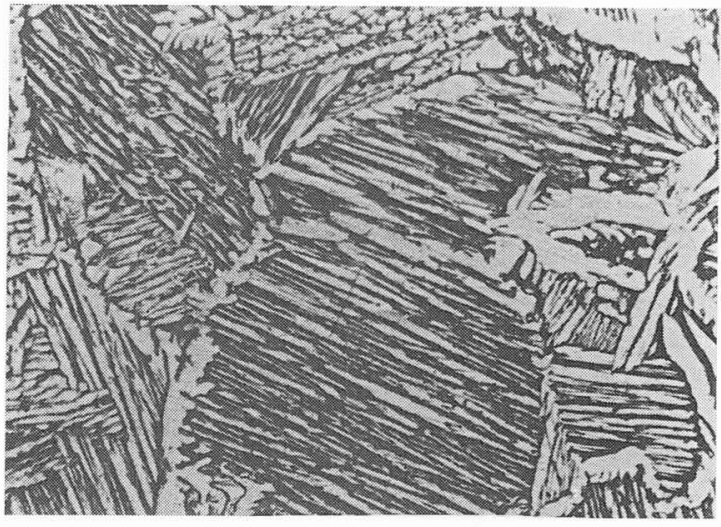

Fig.10. Microstructure formed by repeated $\alpha$ plate nucleation. ( $x 200)$ 